\title{
Práticas de letramento e whatsapp: estudo de caso no contexto de português como língua de acolhimento, à luz da perspectiva ecológica
}

\section{Literacy practices and whatsapp: case study in the context of portuguese as a host language, in the light of the ecological perspective}

DOI: $10.54019 /$ sesv2n3-011

Recebimento dos originais: 05/07/2021

Aceitação para publicação: 20/08/2021

\section{Rosyanne Louise Autran Lourenço}

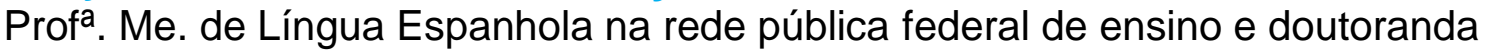
no Programa de Linguística pela Universidade de Brasília (UnB). Endereço institucional: 902/904 - Asa Norte, Brasília - DF, 70790-020.

E-mail: autranrosy@gmail.com

\section{Eliana Barbosa dos Santos}

Profa. . Me. do Núcleo de Ensino e Pesquisa de Português para Estrangeiros pela Universidade de Brasília (UnB).

E-mail: elianagro@yahoo.com.br

\section{RESUMO}

Este artigo visa a apresentar, sob uma perspectiva ecológica de letramento, resultados da análise de práticas sociodiscursivas do processo de ensinoaprendizagem de Português Língua de Acolhimento, de imigrantes refugiados no Brasil, realizadas por meio do WhatsApp. Teoricamente, o estudo circunscrevese às dimensões analíticas de letramento (MOREAU et al., 2013), sob a perspectiva ecológica dos estudos linguísticos (VAN LIER, 2004, 2010), fundamentando-se em pressupostos referentes aos recursos multimodais das tecnologias digitais (LEFFA, 2006; MORAN, 2013) e à função mediadora da linguagem (VIGOTSKI, 1971), em especial, do Português Língua de Acolhimento (BARBOSA; SÃO BERNARDO, 2017) e de suas implicações referentes à noção de afetividade (LEITE, 2012). Metodologicamente, trata-se de estudo qualitativo de caso (STAKE, 1994), de base etnográfica virtual (SANTOS; GOMES, 2013) cuja geração dos dados ocorreu por meio de observação participante (BOGDAN; BIKLEN, 1998) e notas de campo (FETTERMAN, 1998). Sua relevância reside na urgência no processo de imersão de imigrantes refugiados em práticas sociodiscursivas que viabilizem a obtenção de condições mínimas de vida digna e a garantia de autonomia em sua agência no país de destino (COSTA; TAÑ̃, 2018). Os resultados da pesquisa sugerem que a abordagem ecológica de práticas de letramento em ambiente virtual amplia a compreensão das articulações inerentes ao processo de ensino-aprendizagem de línguas, propiciando ao docente melhores condições de promover a autonomia dos 
estudantes, em contexto de imigração, na condução de soluções que atendam às suas necessidades mais prementes, voltadas para as práticas sociais de imersão no país de chegada.

Palavras-chave: Letramento, Perspectiva Ecológica, Ensino e Aprendizagem de Línguas Estrangeiras, Português Língua de Acolhimento, WhatsApp.

\section{ABSTRACT}

This article aims to present, in the light of an ecological perspective of literacy, the results of the analysis of sociodiscursive practices of the teaching-learning process of Portuguese as a Host Language, through WhatsApp by refugee immigrants in Brazil. Theoretically, the study is limited to the ecological perspective of linguistic studies (VAN LIER, 2004, 2010) and analytical literacy dimensions (MOREAU ET $A L ., 2013$ ) based on assumptions regarding the multimodal resources of digital technologies (LEFFA, 2006; MORAN, 2013) and the mediating function of language (VIGOTSKI, 2009) in particular the Portuguese Host Language (BARBOSA; SÃO BERNARDO, 2017) and its implications regarding the notion of affectivity (LEITE, 2012). Methodologically, it is a qualitative case study (STAKE, 1994) with a virtual ethnographic basis (SANTOS; GOMES, 2013) whose data generation occurred through participant observation (BOGDAN; BIKLEN, 1998) and field notes (FETTERMAN, 1998). Its relevance resides in the urgency in the process of refugee immigrants sociodiscursive practices that make it possible to obtain minimum conditions of dignified life and guarantee autonomy at their agency in the destination country (COSTA; TAÑO, 2018). The research results suggest that the ecological approach to literacy practices in a virtual environment broadens the understanding of the articulations inherent to the language teaching-learning process, providing the teacher better conditions to promote the autonomy of the students in the context of immigration, in driving solutions that meet their pressing sociodiscursive needs, focused on social immersion practices in the country of arrival.

Keywords: Literacy, Ecological perspective, Teaching and Learning Foreign Languages, Portuguese Host Language, WhatsApp.

\section{INTRODUÇÃO}

Neste texto, apresentamos os resultados da análise de um recorte de interações sociodiscursivas, entre uma professora e três de seus estudantes imigrantes refugiados, ocorridas por meio da utilização de tecnologias digitais como recurso pedagógico (LEFFA, 2006; MORAN, 2013), no âmbito da aprendizagem móvel (LEFFA, 2006), propiciada pela utilização do WhatsApp, em contexto de ensino-aprendizagem de Português Língua de Acolhimento (BARBOSA; SÃO BERNARDO, 2017) e de suas inter-relações com a afetividade (LEITE, 2012) do aprendiz. 
O arcabouço teórico-analítico insere-se, ainda, nos marcos da função mediadora da linguagem (VIGOTSKI, 1971), das noções de letramento (KLEIMAN, 2008; MATENCIO, 2009) à luz da perspectiva ecológica na esfera dos estudos linguísticos (IÑESTA MENA, 2017; MOREAU ET AL., 2013; VAN LIER, 2004, 2010).

Metodologicamente, trata-se de um estudo qualitativo de caso (STAKE, 1994), de base etnográfica virtual (SANTOS; GOMES, 2013), cuja geração de dados ocorreu por meio de observação participante (BOGDAN; BIKLEN, 1998) e de notas de campo (FETTERMAN, 1998). Para a análise desses dados, utilizamonos do método da triangulação (FLICK, 2009).

Acreditamos que relevância do estudo aqui apresentado reside na necessidade de se pesquisar o contexto de ensino-aprendizagem do Português Língua de Acolhimento (PLAc), em função das condições de vulnerabilidade do público-alvo e da urgência no seu processo de imersão em práticas sociodiscursivas que lhe viabilizem a obtenção de condições mínimas de vida digna e a garantia de autonomia em sua agência no país de destino (COSTA; TAÑO, 2018).

Para melhor orientar o nosso leitor, organizamos seu conteúdo em quatro seções. Na primeira, apresentamos os pressupostos teórico-analíticos pertinentes ao tema proposto; na segunda, explicitamos a metodologia empregada na geração dos dados, na terceira seção, procedemos à sua análise e, na quarta, realizamos nossas considerações finais.

\section{FUNDAMENTAC̄̃O TEÓRICA}

Nesta seção, apresentamos os pressupostos teóricos que norteiam a análise dos dados gerados, organizados em quatros subseções que tratam, respectivamente, de interpretações do construto de letramento e da sua perspectiva ecológica; das tecnologias digitais e da utilização do WhatsApp como ambiente móvel de aprendizagem; da semioticidade da linguagem, com base nas representações semióticas evocadas pelo uso de emojis; e do Português Língua de Acolhimento, com foco na afetividade como um de seus pilares. A seguir, abordamos as concepções de letramento às quais nos filiamos neste estudo.

\section{LETRAMENTO: VISÕES E CONCEITOS}


Entendemos com Kleiman (2008, p. 17-18) a noção de letramento em função de uma gama de tipos de estudos que caracterizam a dinamicidade da sua natureza epistêmico-metodológica. Dessa forma, é possível entendê-lo como: (a) o desenvolvimento e o uso de uma "capacidade metalinguística em relação à própria linguagem"; (b) "uma prática discursiva de determinado grupo social" e (c) em sentido mais amplo, um "conjunto de práticas sociais que usam a escrita como sistema simbólico e como tecnologia, em contextos específicos, para objetivos específicos".

Ao jogo semiótico em que se pauta o agir e o pensar pela linguagem (MATENCIO, 2009), subjaz a sua natureza orgânica, representada pela indissociável relação indivíduo $\leftrightarrow$ sociedade, ao contemplar tanto processos psicocognitivos individuais de processamento dos signos linguísticos (verbais, não verbais e/ou multimodais) quanto processos de convencionalização e de compartilhamento social, por meio de práticas sociodiscursivas, para que a produção de sentidos em interações comunicativas possa, efetivamente, acontecer.

A partir do uso social da leitura e da escrita, emerge a noção de multidimensionalidade do letramento, em função da multiplicidade de modalidades e de práticas historicamente determinadas (KLEIMAN, 2008). No âmbito da didática de línguas ${ }^{1}$, por exemplo, observamos que essa característica se alinha à noção de letramento como conceito operacional, no sentido da sua orientação ao "ensino e à aprendizagem das habilidades comunicativas, independentemente do contexto (salas de língua materna, de segundas ou de línguas estrangeiras, em ambientes de educação formal ou não formal e/ou informal)"² (IÑESTA MENA, 2017, p. 80).

Assim, entendemos, com a autora (2017), que as referidas habilidades envolvem o desenvolvimento da capacidade do indivíduo de expressar-se por escrito e oralmente, em prol da construção da sua própria identidade e das interações sociais que estabelece ao longo da vida. Por essa razão, defendemos, em consonância com Moreau et al. (2013) e Iñesta Mena (2017), sua abordagem ecológica, assunto que tratamos na próxima subseção.

\footnotetext{
${ }^{1}$ Neste texto, noção equivalente ao contexto teórico-metodológico onde ocorrem os processos de ensino e de aprendizagem de línguas, representando uma dimensão da Linguística Aplicada.

2 Todas as traduções realizadas neste artigo são de nossa inteira responsabilidade.
} 


\section{PERSPECTIVA ECOLÓGICA DO LETRAMENTO}

Segundo van Lier (2010, p. 128), o termo ecologia, cunhado no campo da biologia, em 1866, refere-se ao "estudo das relações entre um organismo e todos os demais organismos com os quais ele entra em contato", sendo, desde então, empregado em diversas áreas do conhecimento, entre elas, o da linguagem (HAUGEN, 1972).

Para van Lier (2010), consciência ${ }^{3}$ e linguagem consistem em partes integrantes da ecologia humana, podendo ser entendidas, sobretudo, com relação às atividades sociais e interpessoais. Nessa perspectiva, contempla-se uma visão processual abrangente do desenvolvimento humano, pois, como afirma Paiva (2009, on-line), "A abordagem ecológica não isola os processos sensoriais, cognitivos, afetivos, pois vê todos esses processos de forma interligada nas experiências que o indivíduo vive na sociedade".

Kramsch e Steffensen (2008), por sua vez, defendem que a emergência desse fenômeno é despertada pela disponibilidade de affordances ${ }^{4}$ no ambiente. No caso do estudo aqui apresentado, ela corresponde à utilização do WhastApp como ambiente móvel de aprendizagem, conforme veremos mais adiante.

Cabe-nos salientar que a perspectiva ecológica diz respeito, fundamentalmente, à noção de multiletramentos e à sua estreita relação com as Tecnologias da Informação e da Comunicação (TDICs) ${ }^{5}$, convocando "os usuários da língua a diferentes formas de acesso e de interação, voltadas para a multimodalidade ou para a multissemiose que os textos congregam", exigindo, por sua vez, práticas de linguagem colaborativa (XAVIER; SERAFIM, 2020, p. 27).

Consideramos, ainda, que, na perspectiva ecológica, as práticas de letramento "são fluidas, dinâmicas e mutáveis, assim como a vida e as sociedades das quais fazem parte" (BARTON; HAMILTON, 2000, p. 13), características imanentes à sua proposta de configuração (MOREAU ET. AL, 2013) ${ }^{6}$,

\footnotetext{
${ }^{3}$ Noção entendida como "a totalidade dos esforços (e da sua percepção de sucesso e de fracasso) do indivíduo para atribuir sentidos ao mundo e ao seu lugar nele" (VAN LIER, 2010, p. 133).

${ }^{4}$ No sentido atribuído por van Lier (2004, p. 91), affordance refere-se "àquilo que está disponível para utilização", isto é, a algo com potencialidade de ação, que emerge a partir da interação com o mundo, seja ele físico ou social.

${ }_{6}^{5}$ Assunto tratado mais adiante no texto.

${ }^{6}$ Cabe assinalar que essa configuração resulta de um estudo a respeito dos entendimentos do conceito de letramento no mundo francófono. Acreditamos que a sua utilização é pertinente à análise aqui proposta tendo em vista à abrangência e à organicidade da sua concepção.
} 
apresentada na FIGURA 1, a seguir.

Figura 1 - Perspectiva ecológica do Letramento

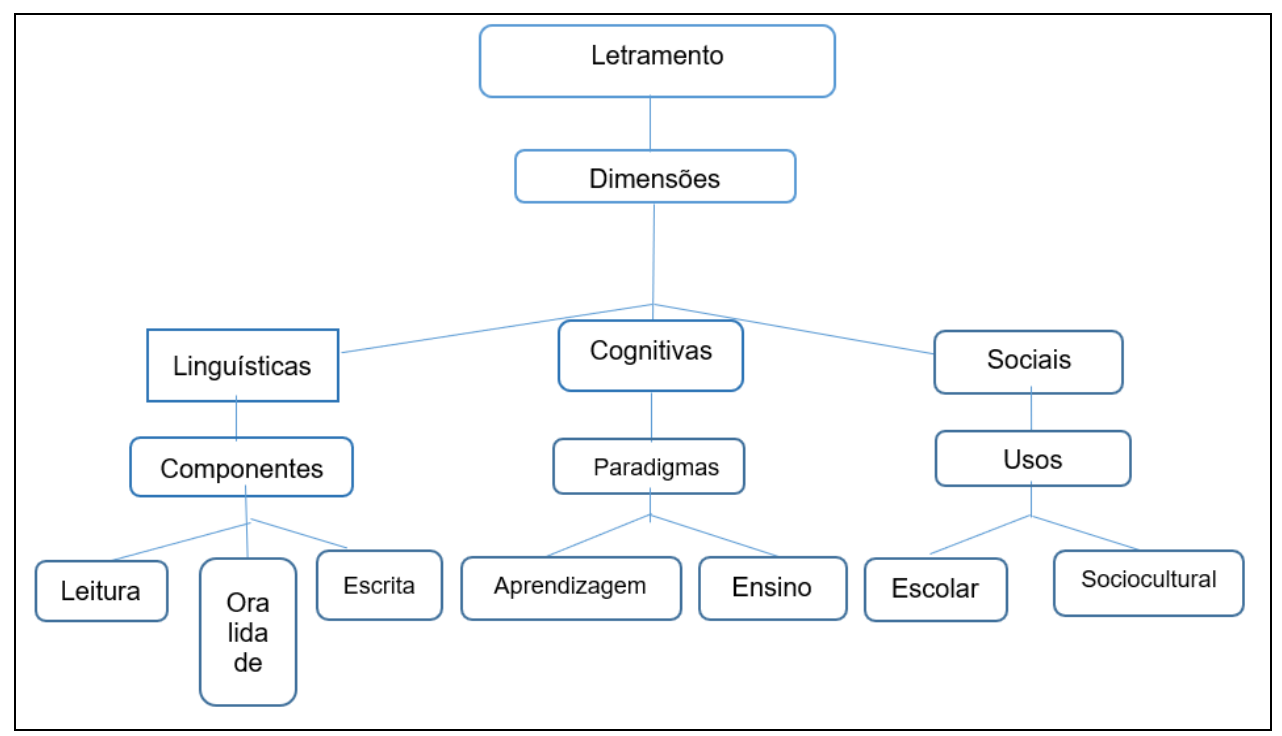

Fonte: Moreau et al. (2013), com adaptações

Na representação acima, identificam-se três macrodimensões de análise dos processos de letramento: (a) a linguística, composta por três veículos de manifestação do código linguístico - a leitura, a oralidade e a escrita; (b) a cognitiva, refletida nos processos de ensino e de aprendizagem, dois paradigmas por meio dos quais os processos de letramento podem ser analisados e (c) a social, relacionada ao âmbito da sua utilização, o entorno escolar e/ou o contexto sociocultural, no sentido de delinear os referidos processos como práticas historicamente situadas.

Sua concepção baseia-se no continuum entre níveis de competências necessárias para a agência do indivíduo em contextos socioculturais específicos. O seu contorno ecológico baseia-se na noção de idiossincrasia, suscitada pela ideia de "validade ecológica" (BERGER; DESROCHERS, 2011, p.17) atribuída a essas competências em função da sua relação a "um conjunto de fontes internas [ao indivíduo] cognitivas, afetivas e sociais, e de fontes externas [a ele], como a família, os amigos e a comunidade" (MOREAU ET AL., 2013, p.4).

Em síntese, portanto, o letramento, sob a ótica ecológica, define-se como

[...] um conjunto de atitudes, de conhecimentos, de habilidades e de competências vinculados à apropriação da cultura e ao acesso ao mundo da escrita. Ele permite a todos os indivíduos adentrar o mundo do Outro, interagir, comunicar-se, pensar, aprender, socializar e 
desenvolver um senso crítico. [...] O letramento se constrói em interação com uma variedade de textos, de gêneros, de suportes tecnológicos ou em papel, de discursos e de práticas. (MOREAU ET AL., 2013, p. 8)

Conforme afirmam os autores, na construção do letramento participam os suportes tecnológicos e os propiciamentos (affordances) advindos do uso das TDICs, entre eles, os originários da utilização do WhatsApp, tema abordado a seguir.

\section{TDICS E WHATSAPP: AFFORDANCES PARA APRENDIZAGEM}

De acordo com Crompton (2013), as pedagogias de aprendizagem do século XXI, ao preconizarem o envolvimento do aprendiz no processo de construção do conhecimento e a sua interação com os meios ambiente e social, abrem espaço para o florescimento da aprendizagem móvel e ubíqua, justificada a partir das percepções e das escolhas da sociedade nesse novo contexto tecnológico.

Ainda segundo a autora, "Os dispositivos móveis reduziram em tamanho e custo e aumentaram em poder, velocidade, memória e funcionalidade", sobretudo, com o apoio das tecnologias wireless (sem fio), provendo possibilidades únicas de affordances às pedagogias centradas no aprendiz (CROMPTON, 2013, p. 10), tais como flexibilidade, acessibilidade e conveniência, tornando o processo de aprender ainda mais contextualizado e cooperativo.

Entre as mídias digitais mais populares relacionadas às aprendizagens móveis, destaca-se o WhatsApp, cujas principais características consistem no caráter simples e intuitivo da sua interface, na possibilidade de criação de grupos de interesse e no envio e no recebimento de mensagens (escritas e/ou audiogravadas), de vídeos e de emojis, figuras produzidas com a tecnologia do sistema Unicode ${ }^{7}$. Todo esse conjunto de atributos caracteriza-o como ferramenta potencializadora da interação entre os seus usuários, implicando a possibilidade de "incorporação simultânea de múltiplas semioses, interferindo na natureza dos recursos linguísticos utilizados" (MARCUSCHI, 2004, p. 13) nos textos que

\footnotetext{
${ }^{7}$ Sistema que, desde a década de 90 do século XX, define um padrão para transmissão de letras e símbolos, permitindo a transformação, em um código único, de todas as formas eletrônicas de comunicação, sejam elas provenientes de letras, números ou símbolos. Informações extraídas do site:

http://www.fenapro.org.br/home/75-artigos-fenapro/831-no-que-consiste-o-sistema-unicode. Acesso em: 25 jul. 2020.
} 
constituem o gênero eletrônico chat, próprio desse tipo de aplicativo. Uma dessas expressões semióticas desvela-se na utilização de emojis, tema da próxima seção.

\section{EMOJIS: RECURSOS SEMIÓTICOS}

Sob o viés mediador da linguagem (VIGOTSKI, 1971), defendemos com Koch (2004) a sua utilização como instrumento de comunicação e como forma de ação e de interação, orientando-se por meio das relações interpessoais dos atores envolvidos.

No âmbito do gênero textual eletrônico chat, por exemplo, os emojis ${ }^{8}$, figuras de origem japonesa, pensadas para transmitirem pensamentos e/ou emoções (NEGISHI, 2014), contribuem sobremaneira para que a linguagem escrita informal que caracteriza esse gênero se torne cada vez mais multimodal (PAIVA, 2016), reflexo das inter-relações pessoais cada vez mais semiotizadas no mundo global deste século.

Segundo Paiva (2016), os emojis apresentam também funções sintáticas e discursivas. Com base nos estudos do linguista computacional Schnoebelen (2012), explicitados em entrevista a Steinmetz (2014), a autora aponta algumas das funções desse recurso, são elas: inserção ao final da frase, funcionando como pontuação (ou depois do ponto final); inclusão entre pensamentos completos; seguimento de uma ordem linear de tempo e de ações por sequenciação de imagens, e aparecimento de posicionamento ou de atitude antes do fato (podendo, por vezes, haver inversão). Entre as funções discursivas, a autora assinala: a substituição de palavra(s); a expressão de emoções; a indicação de afeto; a intensificação/ênfase, marcada pela duplicação da figura e a expressão da ironia.

A seguir, tratamos do objeto de aprendizagem sobre o qual se referem os dados gerados, isto é, o PLAc e a sua inter-relação com a afetividade, uma das manifestações características dos emojis.

\footnotetext{
${ }^{8}$ Segundo informações extraídas do site https://rockcontent.com/blog/emoji/, "a palavra emoji vem da união de “e” (絵), que significa imagem, em japonês, e moji (文字), que significa letra”. Acesso em: 25 jul. 2020. Uma relação de emojis utilizados no aplicativo do WhatsApp pode ser consultada no site https://emojipedia.org/whatsapp/. Acesso em: 16 dez. 2021.
} 


\section{PORTUGUÊS LÍNGUA DE ACOLHIMENTO E SEU PILAR AFETIVO}

No âmbito da Aprendizagem/Aquisição de Línguas (AELin) (ALMEIDA FILHO, 2016), o conceito de língua de acolhimento contempla, em seu bojo, uma relação estreita com as noções de afetividade e, consequentemente, de subjetividade dos atores sociais envolvidos, em geral, imigrantes e refugiados em condição de vulnerabilidade social, em razão de possíveis relações conflituosas nos contatos iniciais com a sociedade no país de chegada (SÃO BERNARDO, 2016).

Segundo Leite (2012), Wallon $(1968,1971,1978)$ afirma que o processo de desenvolvimento humano se centra na interação contínua entre quatro grandes núcleos funcionais, entre eles, a cognição e a afetividade ${ }^{9}$. Esta consiste em um conceito amplo, englobando emoções (de origem biológica) e sentimentos (de origem psicológica), além de "vivências e formas de expressão mais complexas, desenvolvendo-se com a apropriação, pelo indivíduo, dos processos simbólicos da cultura, que vão possibilitar sua representação" (LEITE, 2012, p. 360).

Assim, o aprendiz desempenha um papel ativo nos processos de interação vivenciados, por meio de ações, tais como, elaborar ideias, criar hipótese, analisar e sintetizar, por exemplo. Leite (2012, p. 362) salienta, ainda, que "as práticas de mediação pedagógica10 também são marcadamente afetivas", podendo ser determinantes na maior (vínculo afetivo positivo) ou menor aproximação (vínculo afetivo negativo) do aprendiz com o conteúdo a ser aprendido. Acreditamos que, nesse cenário, a noção de alteridade, isto é, da necessidade da presença do Outro para a construção de sentidos do dizer (MORATO, 2004), torna-se primordial no trabalho com a língua de acolhimento, dado que a existência de empatia é condição sine qua non nos relacionamentos intersubjetivos que ali se estabelecem.

Por essa razão, reconhecemos a inconteste necessidade da integração social do seu público-alvo, com a oferta de oportunidades de aprendizagem da língua portuguesa por intermédio da promoção de práticas sociodiscursivas em contexto de imersão, com a finalidade de acolhê-lo e, assim, poder abrir espaços

\footnotetext{
${ }^{9}$ Para mais informações sobre a teoria desenvolvida por Wallon $(1968,1971,1978)$, consultar as referências.

${ }^{10}$ A esse tipo de prática, o autor se refere como "as relações concretamente estabelecidas e vivenciadas em sala de aula" (LEITE, 2012, p. 362).
} 
para a comunicação diária e promover a sua inserção no mercado de trabalho (BARBOSA; SÃO BERNARDO, 2017). Desse modo, a palavra acolher amplia e expande a sua significação na noção de Língua de Acolhimento, assumindo múltiplos papéis, como ilustra a FIGURA 2, a seguir.

Figura 2 - Língua de acolhimento - noção expandida

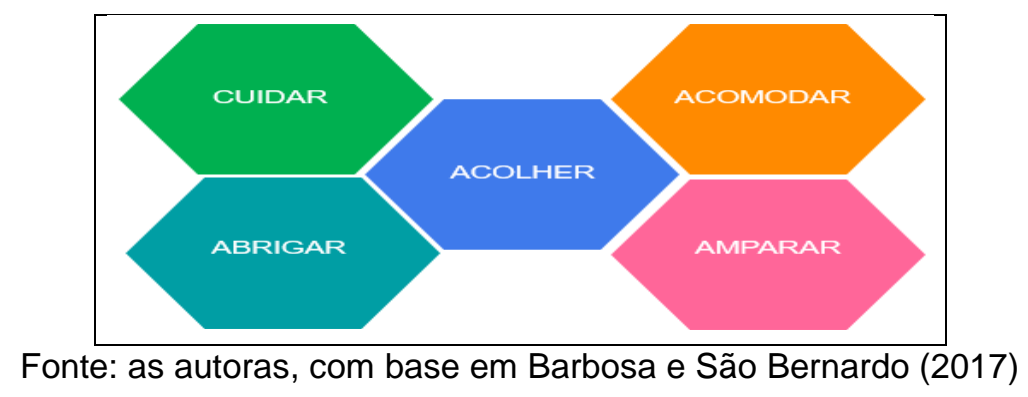

Finalmente, diante dos obstáculos e dos desafios no novo contexto de vida desses indivíduos, Amado (2013) entende que, no âmbito da formação de professores de PLAc, é imprescindível a atitude consciente e solidária do docente profissional, visando à criação de um ambiente de respeito e confiança nas interações ocorridas no contexto educacional. Na próxima seção, apresentamos os fundamentos metodológicos em que se baseia a investigação desenvolvida.

\section{METODOLOGIA}

A pesquisa aqui relatada consiste em um estudo qualitativo de caso (STAKE, 1994), de base etnográfica virtual (SANTOS; GOMES, 2013) cuja geração dos dados ocorreu por meio de observação participante (BOGDAN; BIKLEN, 1998) e de notas de campo (NC) (FETTERMAN, 1998). Para a sua análise, utilizou-se o método da triangulação (FLICK, 2009).

O corpus compõe-se de um recorte de mensagens trocadas, no ano de 2017, por meio do aplicativo WhatsApp, entre a professora-pesquisadora e três de seus alunos do Projeto Pro-Acolher ${ }^{11}$, desenvolvido na Universidade de Brasília (UnB). Entre as atividades gratuitamente ofertadas, encontra-se o curso de PLAc para imigrantes e refugiados em condição de vulnerabilidade social, configurado em três módulos denominados Acolher 1, 2 e 3, com duração de 60h/aula cada.

\footnotetext{
${ }^{11}$ Mais informações no site do Projeto: https://proacolherunb.wixsite.com/proacolher. Acesso em: 16 dez. 2021.
} 
As interações sociodiscursivas analisadas ocorreram em três grupos de WhatsApp, organizados pela professora com o objetivo de viabilizar ampla acessibilidade às atividades de PLAc propostas, são eles: < 1 중 Whatsapp em Português , composto por estudantes do módulo Acolher 1, com pequeno repertório lexical, incipiente domínio morfossintático da língua portuguesa, porém, segurança e disposição em incursões de interação comunicativa; destinado aos estudantes do módulo Acolher 2 e 3, com maiores habilidades em leitura e escrita, maior repertório lexical $\mathrm{e}^{<1}$, cElpe-Brás o interesse de alguns estudantes em preparar-se para obter o certificado de Proficiência de Língua Portuguesa (Celpe-Bras).

A seguir, apresentamos os perfis dos colaboradores que, juntamente com professora-pesquisadora, participam da pesquisa aqui relatada.

Quadro 1 - Perfil dos estudantes participantes da pesquisa

\begin{tabular}{|l|c|c|c|c|}
\hline \multicolumn{1}{|c|}{ Nomes Ficticios } & Tempo Brasil & Pais & Linguas faladas & Idade/sexo \\
\hline Ali & 6 meses & Paquistão & Inglês, Urdu, Pastho, Árabe & $32-\mathrm{M}$ \\
\hline Ishi & 6 meses & Afeganistão & Inglês, Urdu, Pastho, Árabe & $28-\mathrm{M}$ \\
\hline \hline Samuel & 1 ano e 6 meses & Haiti & Francês, Crioulo & $31-\mathrm{M}$ \\
\hline
\end{tabular}

Fonte: dados gerados de pesquisa

\section{ANÁLISE DOS DADOS}

De acordo com os pressupostos teóricos apresentados, o corpus aqui analisado configura-se como um fenômeno de letramento tendo em vista consistir em práticas sociodiscursivas de estudantes imigrantes refugiados, em situação de vulnerabilidade social, que, por meio do gênero textual eletrônico chat (MARCUSCHI, 2004), fazem uso de recursos semióticos multimodais para comunicar-se, acolher e compreender, inclusive metalinguisticamente, a língua portuguesa, vislumbrando sua capacitação para a inserção e a integração à vida cotidiana na sociedade brasileira. É o que podemos observar a partir dos recortes das interações sociodiscursivas, apresentadas no QUADRO 2, a seguir. 
Quadro 2- Expressões do Acolher em contexto de PLAc

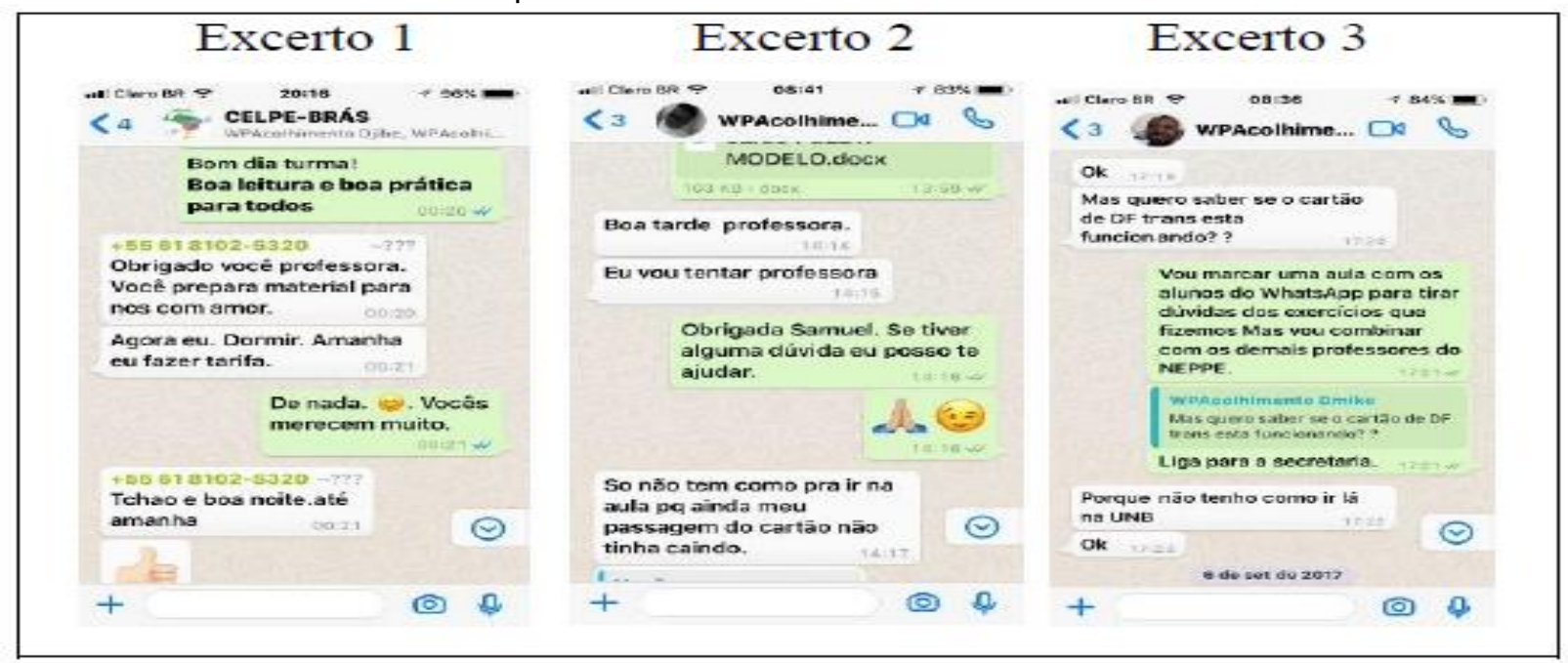

Fonte: dados gerados pela pesquisa

Em função do caráter de acolhimento do contexto linguístico em que os participantes estão imersos, observamos, no EXCERTO 1, que a professora inicia a sua interação com o grupo de forma carinhosa e assertiva, recebendo respostas e comentários que atendem à sua saudação acolhedora. Tal procedimento, a nosso ver, desvela a articulação de dois dos grandes núcleos classificados por Wallon (1968, 1971, 1978), o da afetividade e o da cognição.

O primeiro emerge não somente por meio do registro verbal, marcado pelo uso de palavras com conotação assertiva nos enunciados "Bom dia", "boa leitura" e "boa prática", com os quais, busca transmitir ânimo e despertar o engajamento de todo o grupo, como também pela utilização do emoji - carinha de olhos sorridentes com olhos sorridentes - recurso multimodal, inserido entre dois pensamentos completos, o agradecimento e as palavras de reconhecimento e de incentivo aos estudantes.

Entendemos que essa manifestação discursiva se encontra em estreita relação, sobretudo, com uma prática de mediação pedagógica afetiva, visando a uma maior aproximação com o objeto de estudo (PLAc), em função do contexto social 
em que o processo de ensino-aprendizagem se insere (LEITE, 2012).

Nesse processo de interação com a docente, o papel ativo vivenciado pelo estudante, identificado como Ishi, expressa-se em sua responsividade, por meio do emprego da língua-alvo (L-alvo) seguido do emoji - polegar apontando para cima - cuja função sintática consiste em finalizar a frase com um signo de pontuação (ponto final), imprimindo, assim, um caráter de terminalidade à ideia a ser transmitida (PAIVA, 2016).

No EXCERTO 2, a interação ocorre entre a docente e o estudante Samuel que, assim como Ishi, confirma a sua intenção de realizar a tarefa solicitada ${ }^{12}$. No recorte sociodiscursivo em questão, vale ressaltar o uso dos emojis - pessoa orando com mão palma com palma e carinha piscando - cuja função discursiva (PAIVA, 2016) consiste na sinalização de sentimentos de esperança e de afeto, conjuntamente aos de alegria e de positividade, reforçando, uma vez mais, a expressão da afetividade como um dos pilares no processo de ensinoaprendizagem de PLAc, assim como o da sua apropriação como representação de um processo simbólico (LEITE, 2012).

Ao final desse mesmo excerto e, predominantemente, no EXCERTO 3, sobressaem aspectos sociais relacionados aos contextos pessoais dos estudantes: a necessidade de possuírem o "cartão do DF Trans"13 para que possam se deslocar até o local das aulas. Pensamos que a ocorrência desse fato reforça a relevância da amplitude de significação da noção de acolhimento no contexto de vulnerabilidade social dos colaboradores da pesquisa, pois acreditamos que é inevitável e, inclusive, desejável, que as suas dificuldades práticas de vida sejam manifestadas em espaços de aprendizagem como o propiciado pelos grupos de WhatsApp, uma vez que elas precisam ser socialmente compartilhadas para que possam ser solucionadas de alguma forma. Assim, ganham cores as necessárias ações de cuidar, de abrigar, de acomodar e de amparar, noções contempladas pelo termo acolher, segundo considerações de

\footnotetext{
12 Tarefa escrita, proposta a partir de um objeto de aprendizagem acerca dos benefícios da leitura, segundo registro das NC (12/07/17) da professora-pesquisadora.

${ }^{13}$ O cartão do Passe Livre, administrado pelo órgão público de Transporte Urbano do Distrito Federal (DFTrans), extinto pelo governo em 2020, consiste em uma forma de créditos do Sistema de Bilhetagem Automática que garante aos estudantes da rede pública de ensino a gratuidade do transporte. Atualmente, essas atribuições estão a cargo da Secretaria de Mobilidade e do Banco Regional de Brasília. Informações extraídas do site: https://g1.globo.com/df/distrito-federal/noticia/2019/07/22/dftrans-e-extinto-e-brbassume-sistema-de-bilhetagem-eletronica.ghtml. Acesso em: 16 dez. 2021.
} 
Barbosa e São Bernardo (2017).

No QUADRO 3, a seguir, observamos a fluidez das interações sociodiscursivas em contexto de PLAc, à luz da perspectiva ecológica dessa prática de letramento.

Quadro 3- Fluidez interacional em contexto de PLAc

\begin{tabular}{|c|c|c|c|c|c|}
\hline Excerto 4 & & Excerto 5 & & Excerto 6 & \\
\hline Is there any word for & & $<\geqslant$ Whatsappem portug & & & \\
\hline "sibling" in portuguese? & & I Manda me toto & & $\begin{array}{l}\text { Mas você sabe palivra } \\
\text { para sibling em }\end{array}$ & \\
\hline Irmão= brother $21: 15$ & & $\begin{array}{l}\text { Asalamu alikum, Qari salheb } \\
\text { Rahmat Ali e boa noite. }\end{array}$ & & português. & \\
\hline Quem sabe palivra para & & $\begin{array}{l}\text { tenho seu fotoss? Quem } \\
\text { tenho seu fotos? }\end{array}$ & & $? \quad 21: 28$ & \\
\hline $\begin{array}{l}\text { sibing em portugues } \\
\text { brasilera? }\end{array}$ & & $\because \Leftrightarrow$ & & WPAcolhimento Ali & \\
\hline WPAcolhimento Ali & & & & Nat eu nado sabe $21: 29$ & \\
\hline Manda me foto $21: 17$ & & $\begin{array}{l}\text { Wracolthimento all } \\
\text { Nao tem minha foto da }\end{array}$ & & $+55618102-5320 \sim ?$ & \\
\hline$+55618102-5320$ & & aula ?? & & $\begin{array}{l}\text { Ta. Nao } \\
\text { problema.obrigado }\end{array}$ & \\
\hline WPAcollhimento Ali & & 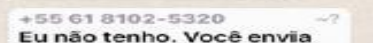 & & $21: 29$ & \\
\hline $\begin{array}{l}\text { Asalamu alikum, Qari } \\
\text { saheb Rahmat Ali e boa } \\
\text { noite. Tudo tranquello! }\end{array}$ & $\theta$ & $\begin{array}{l}\text { email para professora } \\
\text { ingrid. Talvez, Ela ternho. Eu } \\
\text { tenho problemas com verb } \\
\text { e sujetro conjugaçâ. }\end{array}$ & $\Theta$ & $\begin{array}{l}\text { Difference between } \\
\text { avós and avôs? Anybody } \\
\text { explain ,please? }\end{array}$ & $\Theta$ \\
\hline & & $\begin{array}{l}\text { WPAcolhimento Ali } \\
\text { Ahhh ta obrigado }\end{array}$ & & & \\
\hline
\end{tabular}

Fonte: dados gerados pela pesquisa

A fluidez das interações no corpus sob análise sinaliza, a nosso ver, a essência da perspectiva ecológica com a qual observamos essa prática de letramento pois traz à baila tanto as inter-relações idiossincráticas entre os atores sociais e os demais elementos pertinentes ao seu contexto (VAN LIER, 2010) quanto as suas implicações para o processo de ensino-aprendizagem em contexto de imersão desse público específico.

Entendemos que características idiossincráticas dos estudantes estão igualmente marcadas pelo emprego da língua árabe na comunicação de Ishi ao saudar Ali (EXCERTOS 4 e 5), idioma comum a ambos, como forma de acolher o companheiro de sala. Utilizando-se da função medidora da linguagem (VIGOTSKI, 1971) multimodal, Ishi emprega os emojis - mão acenando e carinha feliz, sorrindo - cuja função discursiva (PAIVA, 2016) traduz-se, a nosso ver, por um esforço atitudinal simpático e afetuoso de conquistar o engajamento responsivo do grupo na solicitação feita por ele acerca de uma foto tirada, presencialmente, em sala de aula, conforme registro da NC (08/07/20) da professora-pesquisadora.

A esse respeito, cabe ressaltar a consciência metalinguística de Ishi ao justificar a sua não tentativa de contactar a professora Ingrid para obter a referida foto. $\mathrm{O}$ argumento empregado pelo estudante provém da sua autorreflexão acerca 
da dificuldade em utilizar certos aspectos da língua portuguesa - "Eu tenho problema com verbos e sujeito conjugação" (EXCERTO 5) - para, em seguida, recorrer, novamente à língua inglesa quando volta a referir-se à dúvida referente às marcações lexicais do português avós e avôs, como ilustrado no EXCERTO 6.

As sequências das interações sociodiscursivas 7 a 10, explicitadas no QUADRO 4, a seguir, registram o desenrolar da solução do questionamento do estudante Ishi, que se concretiza, metalinguísticamente, por intermédio da intervenção da professora da turma. Ao longo da sua explicação, percebemos que o papel ativo do aprendiz Ishi no processo de ensino-aprendizagem de PLAc, desvela-se por meio do enunciado multimodal "Ta. Certo.", acompanhado, respectivamente, pelos emojis - carinha feliz e polegar apontando para cima (EXCERTO 8), comportamento reiterado, interativamente, mais adiante, com o enunciado "Ta. Certo agora" (EXCERTO 10).

\begin{tabular}{|c|c|c|c|c|}
\hline Excerto 7 & Excerto 8 & Excerto 9 & \multicolumn{2}{|l|}{ Excerto 10} \\
\hline $\begin{array}{l}\text { WPAcolhimento Peter } \\
\mid+55618102-5320 \\
\text { Difference between arós and }\end{array}$ & $\begin{array}{l}\text { No caso de "siblings" a } \\
\text { tradução em portuguêss } \\
\text { é irmãos/irmãs. Mas o }\end{array}$ & $\begin{array}{l}\text { I have } 3 \text { bothers. I have } \\
2 \text { sisters. How much } \\
\text { brothers do I have? I }\end{array}$ & \multicolumn{2}{|c|}{$\begin{array}{l}\text { Sim. Usamos irmão para } \\
\text { brother e para siblings. }\end{array}$} \\
\hline explain, ,please? & avaliado de acordo corm & $\begin{array}{l}\text { have } 3 \text { brothers. How } \\
\text { much sisters do I have? I }\end{array}$ & \multirow{2}{*}{$\begin{array}{l}+55618102-5320 \quad \rightarrow ? \\
\text { Ta. Certo agora. }\end{array}$} & \\
\hline Avó= grand mother and & 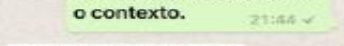 & have 2 sisters. How & & \\
\hline avô= grand father 21.42 & $455618102-5320$ & $\begin{array}{l}\text { much siblings do I have? } \\
\text { I have } 5 \text { siblings. }\end{array}$ & \multicolumn{2}{|l|}{ WPAcolhimento Peter } \\
\hline +55618102-5320 ? & Ta. Certo. +21440 & Paul has one brother & \multirow{2}{*}{\begin{tabular}{|l|}
+55 61 $8102-5320$ \\
Português usa irmaío para \\
brother e sibling. Usa um \\
palivra para duas ok. Tamb...
\end{tabular}} & \\
\hline $\begin{array}{l}\text { Por favor, vejo meu } \\
\text { pergunta. }\end{array}$ & \multirow{4}{*}{$\begin{array}{l}\text { BROTHER designa o } \\
\text { gênero masculino e } \\
\text { SISTER o gênero } \\
\text { feminino. SIBLING } \\
\text { designa o fato de se } \\
\text { possuir a filiação em } \\
\text { comum, independent } \\
\text { do gênero. }\end{array}$} & Paul has one sibling. & & \\
\hline $\begin{array}{l}\text { +55 } 618102-5320 \\
\text { Is there any word for "sibiing" } \\
\text { in portuguese? }\end{array}$ & & $\begin{array}{l}\text { Mark has two sisters. } \\
\text { Mark has two siblings. }\end{array}$ & \multicolumn{2}{|l|}{$\begin{array}{l}\text { Palavra } \\
+55618102-5320 \quad-?\end{array}$} \\
\hline $\begin{array}{l}\text { O significado de } \\
\text { qualquer palavra vai }\end{array}$ & & $\begin{array}{l}\text { Mary has sisters and } \\
\text { brothers. Mary has } \\
\text { siblings. }\end{array}$ & $\begin{array}{l}\text { WPAcolhimento Peter } \\
\text { Palavra }\end{array}$ & $\odot$ \\
\hline depender do contexto. & & siblings. $\quad 27180 \mathrm{r}$ & \multicolumn{2}{|l|}{ Ta, obrigado você. ... } \\
\hline
\end{tabular}

Fonte: dados gerados pela pesquisa

A análise desses excertos sob a perspectiva ecológica do letramento (MOREAU ET AL., 2013) nos permite observar a sua emergência a partir das interrelações constantes entre as suas três macrodimensões: a) linguisticamente, seus três componentes caracterizam o gênero eletrônico textual chat: Além da leitura e da escrita, naturalmente a ele inerentes, entendemos que traços da modalidade oral da comunicação podem ser contemplados, de certa forma, por meio de suas marcas discursivas, impressas pelo uso dos emojis, em função da sua composição imagética representativa de expressões corporais plenas de significados.

Essas inter-relações linguísticas, por sua vez, atendem às demandas da 
dimensão cognitiva (b), presentes na articulação intrínseca entre os processos de ensino-aprendizagem em questão, o do PLAc. Nesse sentido, sugerimos a sua renomeação para dimensão psicocognitiva, em função da impossibilidade de se apartar a esfera psíquica da esfera intelectual na visão processual do desenvolvimento humano e da sua mútua influência (LEITE, 2012; PAIVA, 2009), conforme defendemos neste estudo.

Finalmente, na dimensão social da perspectiva ecológica do letramento, compartilhamos com Kramsch e Steffensen (2008), a sua emergência por meio da utilização do WhatsApp, como ambiente móvel de aprendizagem ubíqua, dada a ocorrência da sua utilização dentro e fora de sala de aula ${ }^{14}$. Observamos, ainda, que, em todos os excertos analisados, a sua validade ecológica (BERGER, DESROCHERS, 2011) baseia-se nas idiossincrasias dos colaboradores da pesquisa, de modo que o fenômeno do letramento se delineia a partir da articulação das competências necessárias para a sua agência com relação às especificidades do PLAc em contexto de imersão brasileiro.

Competências essas que se referem às inter-relações entre as suas reflexões (meta)linguísticas, as suas atitudes de afeto, em função das formas multissemióticas empregadas na comunicação entre eles e com a professora, e a sua interculturalidade, à medida que se utilizam das línguas árabe e inglesa para acolher os colegas e para sanar dificuldades de compreensão na L-alvo.

\section{CONSIDERAÇÕES FINAIS}

Neste texto, apresentamos as análises de interações sociodiscursivas entre uma professora e seus alunos, imigrantes refugiados, aprendizes de português língua de acolhimento, realizadas por meio do WhatsApp, com o objetivo de desvelar a organicidade dessa prática de letramento sob a sua perspectiva ecológica.

O arcabouço teórico norteador da análise nesse estudo de caso qualitativo (STAKE, 1994), fundamenta-se, sobretudo, nas noções de letramento (KLEIMAN, 2008; MATENCIO, 2009) e na sua perspectiva ecológica, a partir dos pressupostos de Iñesta Mena (2017), Moreau et al. (2013) e van Lier (2004, 2010); no construto do Português Língua de Acolhimento (BARBOSA; SÃO BERNARDO,

\footnotetext{
${ }^{14}$ As NC da professora-pesquisadora (12/07/17) registram que a dúvida linguística de Ishi surgiu quando ele estudava em sua casa.
} 
2017) e nas suas implicações atinentes à noção de afetividade (LEITE, 2012) do aprendiz de línguas.

Os resultados de pesquisa sugerem que a abordagem ecológica de práticas de letramento de PLAc, em ambiente virtual, amplia a compreensão das articulações psicolinguísticas e sociodiscursivas dos atores sociais envolvidos, as quais são inerentes ao processo de ensino-aprendizagem de línguas em contexto de imigração, propiciando ao docente melhores condições de promover a autonomia desses estudantes na condução de soluções que atendam às suas necessidades mais prementes, voltadas para as práticas sociais de imersão no país de chegada.

Por último, convidamos o nosso leitor à reflexão acerca da relevância das práticas de letramento sob o viés ecológico em função da sua abrangência e abertura a novas formas sociais de produção e de recepção do texto, seja em sua forma escrita, oral e/ou multimodal, e o convidamos a expandir, cada vez mais, o olhar crítico sobre essas múltiplas possibilidades de expressão da agência do homem no mundo, considerando-o em uma visão holística, isto é, na sua integralidade ecológica, emergente das articulações entre as suas dimensões física, cognitiva, psíquica e sociocultural. 


\section{REFERÊNCIAS}

ALMEIDA FILHO, J. C. P. Competências por dentro: estrutura e funcionamento das competências de professores e aprendizagens de línguas. São Paulo: Pontes, 2016.

BARBOSA, L. M. A.; SÃO BERNARDO, M. A. LÍNGUA DE ACOLHIMENTO. Dicionário Crítico de Migrações Internacionais. Brasília DF: Editora da UnB, 2017.

BERGER, M. J.; DESROCHERS, A. L'évaluation de la littératie. Ottawa: Les Presses de l'Université d'Ottawa, 2011.

BOGDAN, R. C; BIKLEN, S. K. Qualitative research for education: an introduction to theory and methods, 3 ed. Boston: Allyn \& Bacon, 1998.

CROMPTON, H. A historical overview of mobile learning: Toward learner-centred education, In: BERGE, Z. L.; L. Y. MUILENBUR (eds.). Handbook of Mobile Learning. UK: Routledge, 2013. Cap. 1. p. 3-14. Disponível em: https://www.researchgate.net/publication/263852116 A historical overview of mobile learning Toward learner-centered education. Acesso em: 15 dez. 2021.

FETTERMAN, D. M. 1998. A Wilderness Guide: Methods and Techniques. Ethnography step by step, p. 41-72.

FLICK, U. Introdução à pesquisa qualitativa. (Trad.) Joice Elias Costa, $3^{a}$ ed. Porto Alegre: Artmed, 2009.

HAUGEN, E. The ecology of language. In: DIL, A. S. (ed.) The Ecology of Language: Essays by Einar Haugen. Stanford, CA: Stanford University Press, 1972.

IÑESTA MENA, E. M. Revisión sobre literacidad como noción multidimensional para una Didáctica de Lenguas inclusiva. Porta Linguarum, 27, enero 2017. Disponível em: http://www.ugr.es/ portalin/articulos/PL numero27/6 Eva\%20M\%20Inesta.pdf.

Acesso em: 10 nov. 2021.

KLEIMAN, A. B. Os estudos de letramento e a formação do professor de língua materna. Linguagem em (Dis)curso, v. 8, n. 3, set./dez. 2008. Disponível em: http://www.scielo.br/pdf/ld/v8n3/05.pdf. Acesso em: 13 jul. 2021.

KOCH, I. G. V. A Inter-Ação pela Linguagem. São Paulo: Contexto, 2004.

KRAMSCH, C.; STEFFENSEN, S. V. Ecological Perspectives on second Language acquisition and Socialization. In: DUFF, P. A.; HORNBERGER, N. H. (eds.). Encyclopedia of Language and Education, 2nd. Edition, v. 8: Language Socialization, p. 17-28, 2008. 
LEITE, S. A. S. Afetividade nas práticas pedagógicas. Temas em Psicologia, v. 20, n. 2, p. 355-368. Disponível em: http://pepsic.bvsalud.org/pdf/tp/v20n2/v20n2a06.pdf. Aceso em: 02 ago. 2021.

MARCUSCHI, L. A. 2004. Gêneros textuais emergentes no contexto da tecnologia digital. Hipertexto e gêneros digitais. Texto da Conferência pronunciada na $50^{\mathrm{a}}$ Reunião do GEL - Grupo de Estudos Linguísticos do Estado de São Paulo, USP, São Paulo, 23-25 de maio de 2002. Disponível em: https://pt.scribd.com/document/57043043/Generos-Textuais-Emergentes-NoContexto-Da-Tecnologia-Digital. Acesso em: 14 dez. 2021.

MATENCIO, M. L. M. Estudos de letramento e formação de professores: retomadas, deslocamentos e impactos. Calidoscópio, v. 7, n. 1, jan/abr 2009. Disponível em: https://www.redalyc.org/articulo.oa?id=571561886002. Acesso em: 13 out. 2021.

MORATO, E. M. O interacionismo no campo linguístico. In: MUSSALIM, F.; BENTES, A. C. Introdução à linguística: fundamentos epistemológicos, vol. 3, p. 311-351. São Paulo: Ed. Cortez, 2004.

MOREAU, C. A.; HÉBERT, M.; LEPINE, M.; RUEL, J. Revue CNRIS, vol. 4, n. 2 , abril 2013. Disponível em: http://cdeacf.ca/actualite/2013/06/19/concept-litteratiefrancophonie-disent-definitions. Acesso em: 13 set. 2021.

NEGISHI, M. Meet Shigetaka Kurita, the Father of Emoji. Wall Street Journal, 2014.

Disponível em: https://blogs.wsj.com/iapanrealtime/2014/03/26/meet-shigetakakurita-the-father-of-emojil. Acesso em 25 jul. 2021.

PAIVA, V. L. M. O. A Linguagem dos Emojis. Trab. Ling. Aplic., v. 55, n. 2, p. $\begin{array}{ll}\text { 379-399, maio/ago. } & 2016 \text {. } \\ \text { https://www.scielo.br/scielo.php?pid=S0103- }\end{array}$

$18132016000200379 \&$ script=sci abstract\&tlng=pt. Acesso em: 15 dez. 2021.

SANTOS F. M.; GOMES S. H. Etnografia virtual na prática: análise dos procedimentos metodológicos observados em estudos empíricos em cibercultura. VII SIMPÓSIO NACIONAL DA ASSOCIAÇÃO BRASILEIRA DE CIBERCULTURA - ABCiber. Paraná. Anais..., 2013. Disponível em: em http://www.abciber.org.br/simposio2013/anais/pdf/Eixo 1 Educacao e Process os de Aprendizagem e Cognicao/26054arq02297746105.pdf. Acesso em: 12 ago. 2021.

SÃO BERNARDO, M. A. Português como língua de acolhimento: um estudo com imigrantes e pessoas em situação de refúgio no Brasil. Tese (Doutorado em Linguística). Universidade Federal de São Carlos. 206 f. São Carlos, 2016. Disponível em: https://repositorio.ufscar.br/handle/ufscar/8126?show=full. Acesso em: 18 nov. 2021. 
STAKE, R. E. Case studies. In: DENZIN, N. K.; LINCOLN, Y. S. (Eds.). Handbook of qualitative research, p. 236-247. London: Sage, 1994.

STEINMETZ, K. (2014). Here Are Rules of Using Emoji You Didn't Know You Were Following. In: TIME Exclusive. Disponível em: time.com/2993508/emoji-rulestweets/. Acesso em: 15 dez. 2021.

SCHNOEBELEN, T. J. Emotions are relational: positioning and the use of affective linguistic resources. Tese de Doutorado em Linguística. Universidade de Stanford, Stanford, Estados Unidos, 2012.

VAN LIER, L. The Ecology and Semiotics of Language Learning: a Sociocultural Perspective. Dordrecht: Kluwer Academic Publishers, 2004. 249p. VAN LIER, L. The Relationship Between Consciosuness, Interaction and Language Learning, p. 128-145, 2010. Disponível em: https://www.tandfonline.com/doi/abs/10.1080/09658419808667105?journalCode =rmla20. Acesso em: 14 jul. 2021.

VIGOTSKI, L. S. Pensamento e Linguagem, 1971. Disponível em: http://www.ebooksbrasil.org/adobeebook/vigo.pdf. Acesso em: 25 de ago. 2021.

XAVIER, M. M.; SERAFIM, M. L. O WhatsApp impactando novas possibilidades de ensinar e de aprender no contexto acadêmico. São Paulo: mentes Abertas, 2020. 132p.

WALLON, H. A evolução psicológica da criança. Lisboa: Edições 70, 1968.

WALLON, H. As origens do caráter na criança. São Paulo: Difusão Europeia do Livro, 1971.

WALLON, H. Do acto ao pensamento. Lisboa: Moraes Editora, 1978. 